\title{
Techniczno-ekonomiczne aspekty spawania wiązką laserową rur ożebrowanych w kotłach energetycznych
}

\section{Technical and economic aspects of fin tubes used in power boilers welded by laser}

\section{Streszczenie}

Przedstawiono techniczno-ekonomiczne aspekty wykorzystania laserów dużej mocy do produkcji rur ożebrowanych. Omówiono technologię spawania wiązką lasera rur ożebrowanych oraz dokonano porównania spawania laserowego z metodą MAG i zgrzewania HF tych rur. Zaprezentowano ekonomiczne korzyści z zastosowania technologii spawania laserowego w stosunku do metody spawania łukowego MAG.

\section{Abstract}

This paper presents technical and economic aspects of using high power lasers for the production of fin tubes. Discussed laser welding technology of fin tubes and made comparison laser welding to MAG and HF welding of mentioned tubes. It was also shown economic benefits of laser welding technology against MAG arc welding methods.

\section{Techniczne aspekty zastosowania i wytwarzania rur ożebrowanych}

Do budowy wymienników ciepła stosowanych w nowoczesnych rozwiązaniach konstrukcyjnych energetycznych zespołów kotłowych wykorzystuje się rury ożebrowane. W zależności od parametrów pracy (ciśnienia i temperatury), czynnika roboczego oraz spalin rury ożebrowane mogą być podgrzewaczami, ekonomizerami albo przegrzewaczami. Zastosowanie ich wyraźnie zwiększa sprawność energetyczną kotłów. Sprawność termiczna rur ożebrowanych jest 2,5 razy większa od rur gładkich i 1,5 razy większa od rur Faviera.

Zastosowanie rur ożebrowanych umożliwia: oszczędność energii i obniżenie jednostkowych kosztów w procesie eksploatacji kotłów przemysłowych,

Dr inż. Wojciech Gawrysiuk, mgr inż. Adam Troszka - Energoinstal. odzyskiwanie ciepła kondensacji i jego celowe wykorzystanie, minimalizację strat energii przez obniżenie temperatury gazów spalinowych oraz zwiększenie sprawności przy równoczesnym zmniejszeniu gabarytów i ciężaru kotła.

Rury ożebrowane z żebrem ciągłym bądź nacinanym (rys. 1), spawanym na całej długości, są wykonywane przez automatyczne spawanie w osłonie gazów aktywnych elektrodą topliwą MAG lub przez zgrzewanie prądami wysokiej częstotliwości HF. Łączenie

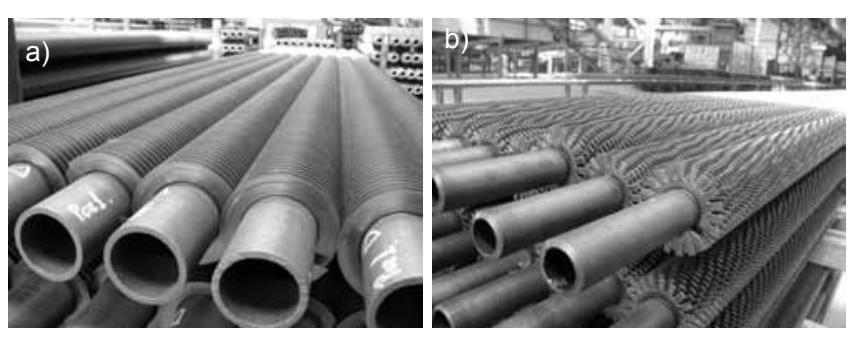

Rys. 1. Rury ożebrowane spawane laserem dużej mocy: a) z żebrem ciągłym, b) z żebrem nacinanym

Fig. 1. High Power laser welded fin tubes: a) with solid fin, b) with serrated fin 


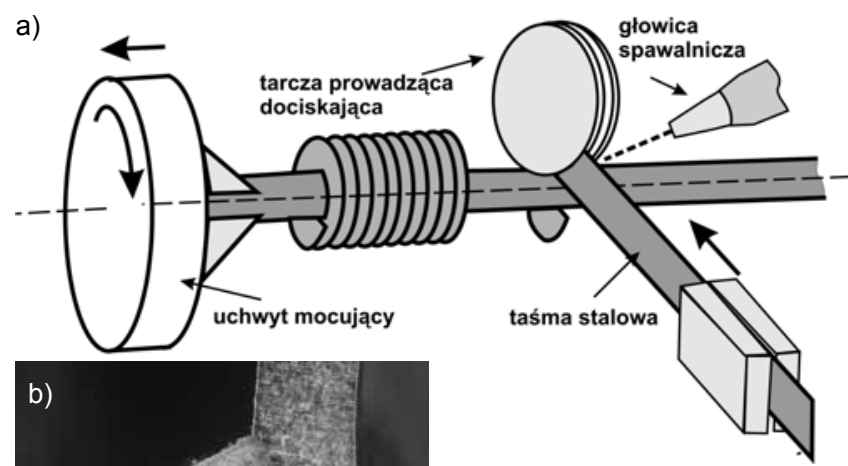

Rys. 2. Spawanie rur ożebrowanych metodą MAG: a) schemat procesu, b) spoina pachwinowa rura-żebro, pow. $5 x$

Fig. 2. MAG welding of fin tubes: a) the scheme of process, b) tube-fin fillet weld, magn. $5 x$
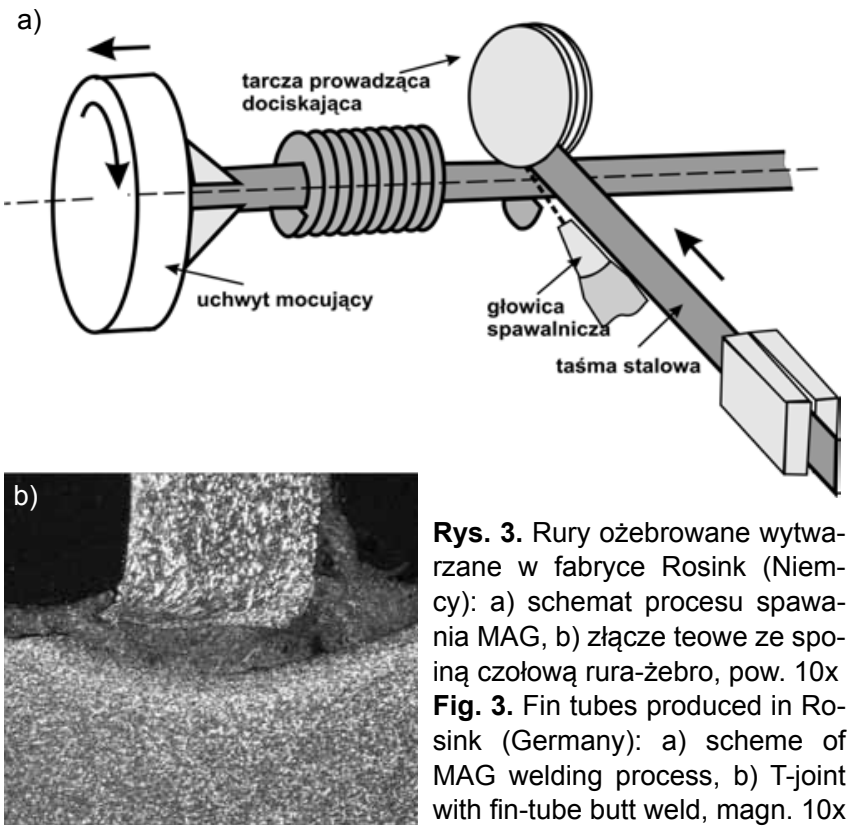

Rys. 3. Rury ożebrowane wytwarzane w fabryce Rosink (Niemcy): a) schemat procesu spawania MAG, b) złącze teowe ze spoiną czołową rura-żebro, pow. 10x Fig. 3. Fin tubes produced in Rosink (Germany): a) scheme of MAG welding process, b) T-joint with fin-tube butt weld, magn. 10x

a)

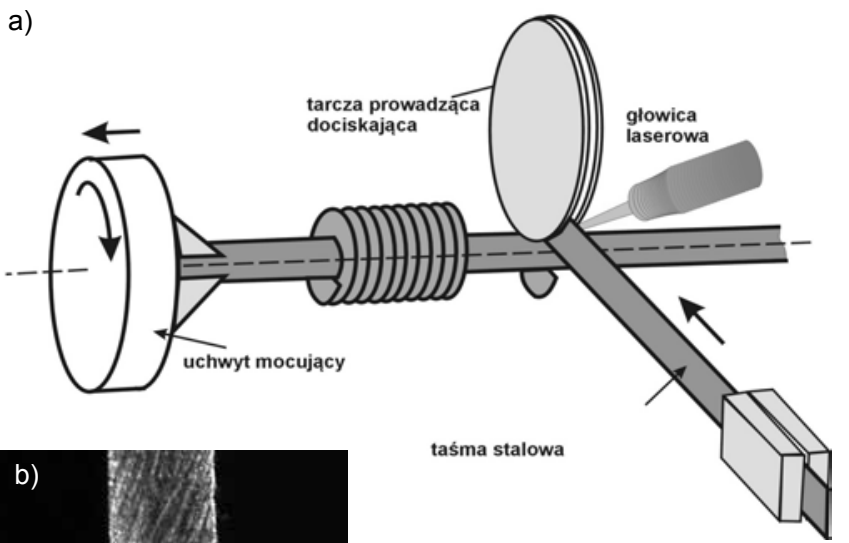

Rys. 4. Rury wytwarzane w Energoinstalu: a) schemat procesu spawania wiązką laserową, b) złącze teowe ze spoiną czołową rura (P22)-żebro (taśma nierdzewna), pow. $5 x$

Fig. 4. Fin tubes produced in Energoinstal: a) the scheme of laser welding process, b) T-joint with fin (P22)-tube (stainless band) butt weld, magn. 10x

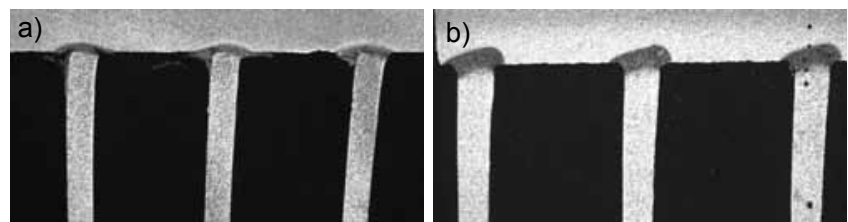

Rys. 5. Makrostruktura złączy w rurze ożebrowanej: a) spawanie metodą MAG: b) spawanie wiązką laserową, pow. $5 x$

Fig. 5. Macrostructure of welds in fin tube: a) MAG welding, b) laser beam welding, magn. $5 x$

odbywa się za pomocą spoiny pachwinowej lub spoiny/ zgrzeiny czołowej wykonywanej pod żebro.

Sposób pierwszy charakteryzuje się niską wydajnością (rys. 2), natomiast sposób drugi nie gwarantuje odpowiedniej jakości złącza spawanego/zgrzewanego - występują niezgodności spawalnicze, takie jak podtopienia, przyklejenia, brak przetopu oraz rozpryski (rys. 3).

W celu porównania właściwości wytrzymałościowych i jakości rur ożebrowanych ze stali P235 oraz taśmy DC01 o grubości $1 \mathrm{~mm}$, spawanych wiązką lasera i metodą MAG, przeprowadzono badania wizualne i makroskopowe, pomiar twardości HV5 oraz próbę rozciągania.

Badania makroskopowe rury ożebrowanej spawanej metodą MAG oraz spawanej wiązką lasera wykonano przy powiększeniu 5x (rys. 3, 4).

W połączeniu rura-żebro spawanym metodą MAG stwierdzono liczne przyklejenia i braki przetopu (rys. 5a), natomiast w przypadku połączenia spawanego wiązką lasera nie stwierdzono niezgodności poniżej poziomu jakości B wg normy PN EN ISO 13919 (rys. 5b).

Ze względu na niestandardowe wymiary i kształt próbek, badania wytrzymałości na rozciąganie wykonano w specjalnie przygotowanym do tego celu uchwycie i szczękach (rys. 6).

W przypadku rur spawanych metodą MAG nie było możliwe przygotowanie próbek do badań ze względu

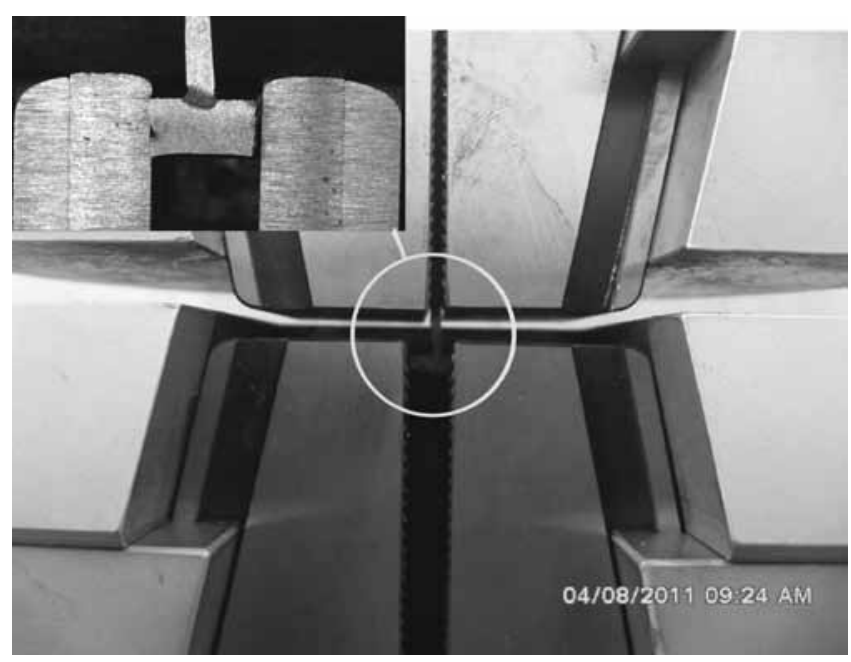

Rys. 6. Próba rozciągania złącza rura (P235)-żebro (DC01) wykonanego wiązką lasera, widoczne usytuowanie w szczękach maszyny wytrzymałościowej oraz próbki po zerwaniu

Fig. 6. Tension test of laser beam welded tube (P235)-fin (DC01), position in grip of testing machine, and specimen after testing 
na niewystarczające połączenie metaliczne pomiędzy rurą a żebrem, które ulegało zniszczeniu („odchodziło”) przy próbie cięcia rury ożebrowanej na pile. Taśma stosunkowo łatwo oddzielała się od rury przy ręcznej próbie wyłuskiwania (rys. 7).

Podczas prób rozciągania wykonanych na trzech próbkach spawanych wiązką lasera uzyskano wytrzymałość na rozciąganie $\mathrm{R}_{\mathrm{m}}$ ok. $317 \mathrm{MPa}$, a zerwanie nastąpiło poza spoiną (rys. 8).

Na rysunku 9 przedstawiono wyniki pomiaru twardości HV 5 połączenia rura-żebro wykonanego metodą MAG (a) i wiązką lasera (b).

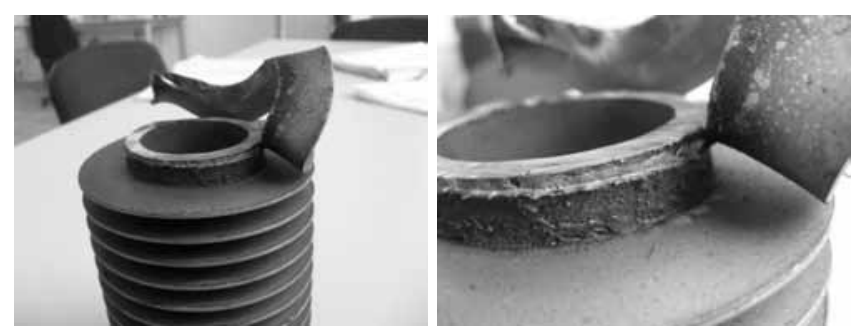

Rys. 7. Połączenie pomiędzy rurą a żebrem wykonane metodą MAG Fig. 7. Joint of tube and fin made by MAG method

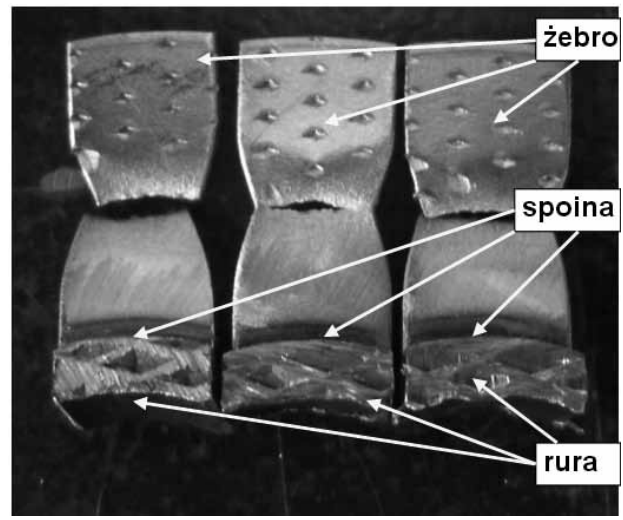

Rys. 8. Próbki po próbie rozciągania - zerwanie poza spoiną (spawanie wiązką lasera)

Fig. 8. Specimen after tensile test - break outsider the weld (laser beam welding)
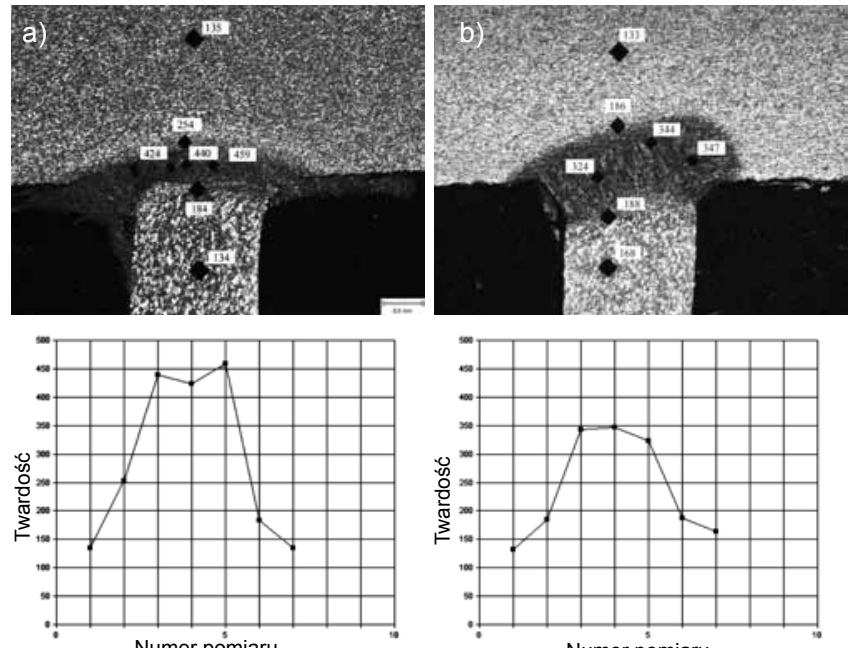

Rys. 9. Rozkłady twardości HV 5 połączenia rura (P235)-żebro (DC01) wykonanego: a) metodą MAG, b) wiązką lasera

Fig. 9. Hardness HV 5 distribution In tube (P235)-fin (DC01) made by: a) MAG method, b) laser beam welding
Największą twardość połączenia rura-żebro wykonanego metodą MAG ma sama spoina - wynosi ono odpowiednio: 424, 440 i 459 HV (rys. 9a), co znacznie przekracza dopuszczalną wartość, która dla I grupy materiałowej wg PN-EN ISO 15614-1 wynosi $380 \mathrm{HV}$. Rura ożebrowana wykonana laserem również charakteryzuje się najwyższą wartością twardości w spoinie, ale nie przekracza granicznej wartości 380 HV (rys. 9b).

\section{Ekonomiczne aspekty spawania rur ożebrowanych laserem}

Przy wdrażaniu spawania laserowego największym nakładem finansowym, jaki najczęściej należy ponieść, jest zakup źródła laserowego. Przeciętnie $1 \mathrm{~kW}$ mocy lasera to wydatek rzędu $60 \div 80$ tys. euro. Całkowite koszty użytkowania laserów na ciele stałym, wliczając w to: nakłady na zakup lasera, części zamienne, koszty energii, koszt zatrudnienia pracownika oraz koszt zajmowanej powierzchni, wynoszą $18 \div 21$ euro/h (rys. 10).

Zakup źródła laserowego o mocy $8 \mathrm{~kW}$ wraz z $50 \mathrm{~m}$ światłowodem oraz głowicą laserową to wydatek ok. $2 \mathrm{mln}$ zł. Dla wielu przedsiębiorstw stanowi to główną barierę przy wdrażaniu technologii laserowych do spawania i wybierają one tańsze urządzenia do spawania łukowego, np. MAG za kilkanaście tys. zł. Jeśli jednak wykonany zostanie rachunek ekonomiczny i porówna się obie metody spawania dla konkretnego zastosowania, można dojść do zaskakujących wniosków. W tablicy zestawiono wyniki analizy ekonomicznej zastosowania spawania laserowego i tradycyjną metodą spawania łukowego MAG (rys. 5a) rur ożebrowanych długości $10 \mathrm{~m}$ dla różnej liczby zwojów na $1 \mathrm{~m}$ rury. Dla rury o średnicy $44,5 \mathrm{~mm}$, długości $10 \mathrm{~m}$ i liczby zwojów 250 na $1 \mathrm{~m}$ rury, długość połączenia spawanego wynosi ok. $350 \mathrm{~m}$. Przeciętnie w kotle odzysknicowym w zależności od jego parametrów pracy wykorzystuje się średnio 1000 $\div 1200$ rur ożebrowanych, co daje do wykonania $350 \div 420 \mathrm{~km}$ połączenia spawanego rura-żebro.

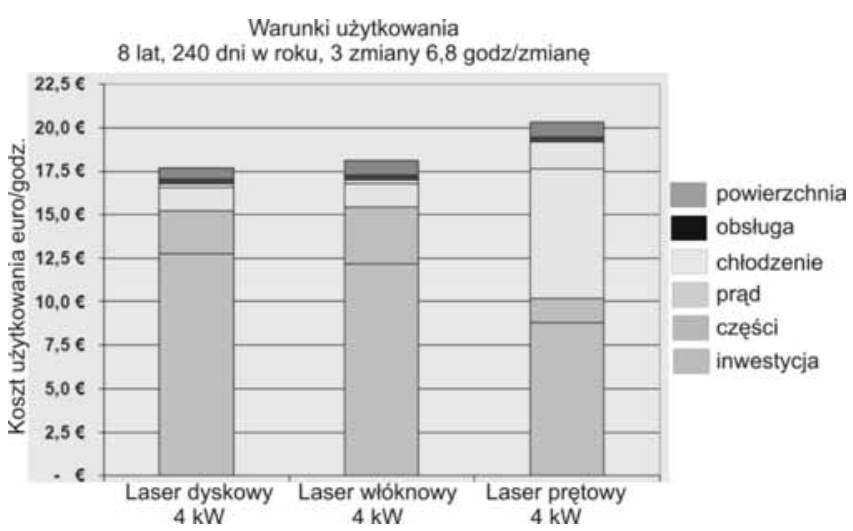

Rys. 10. Porównanie kosztów użytkowania laserów na ciele stałym [1] Fig. 10. Cost comparison of using solid state lasers [1] 
Tablica. Analiza porównawcza kosztów spawania metodą MAG i laserem rur ożebrowanych o długości zwojów 10 m Table. Comparison analysis of welding cost of $10 \mathrm{~m}$ length coin fin tube by MAG method and laser beam welding

\begin{tabular}{|c|c|c|c|c|c|}
\hline $\begin{array}{c}\text { Średnica rury } \\
\text { D, mm }\end{array}$ & $\begin{array}{c}\text { Liczba zwojów Z na } \\
1 \text { m rury }\end{array}$ & $\begin{array}{c}\text { Czas spawania, min } \\
\text { MAG }\end{array}$ & $\begin{array}{c}\text { Czas spawania, min } \\
\text { laser }\end{array}$ & $\begin{array}{c}\text { Koszt całkowity, zł } \\
\text { MAG }\end{array}$ & $\begin{array}{c}\text { Koszt całkowity, zł } \\
\text { laser }\end{array}$ \\
\hline 44,5 & 250 & 139,2 & 22,7 & 27,85 \\
\hline 44,5 & 200 & 111,3 & 18,2 & 77,80 \\
\hline 44,5 & 150 & 83,5 & 13,6 & 58,35 \\
\hline 38,0 & 250 & 96,2 & 16,7 & 73,41 \\
\hline 38,0 & 200 & 77,0 & 13,3 & 21,04 \\
\hline 38,0 & 150 & 57,7 & 10,0 & 58,73 \\
\hline
\end{tabular}

Koszt drutu - ilość zużytego drutu x koszt (6,12 zł/kg); koszt gazu - ilość zużytego gazu x koszt (0,0095 zł/l); koszt pracy operatora - czas spawania x koszt (0,20 gr/min); amortyzacja (laser 16000 PLN/mies.), (MAG 208 PLN/mies.); koszt energii elektrycznej 0,55 zł/kWh

Analiza porównawcza kosztów spawania laserowego i spawania łukowego metodą MAG rur ożebrowanych, zawarta w tablicy I, wykazała 3,5-krotne zmniejszenie kosztów wytwarzania rur ożebrowanych metodą laserową przy zwiększeniu wydajności o ponad $600 \%$. Jedna linia do spawania zarówno laserowego, jak i metoda MAG zajmuje ok. $100 \mathrm{~m}^{2}$. W celu wyrównania wydajności spawania laserowego i metodą MAG należałoby dodatkowo zakupić kolejne 5 linii i zatrudnić kolejnych 5 operatorów, a same linie zajmowałyby ok. $1000 \mathrm{~m}^{2}$ powierzchni hali produkcyjnej.

\section{Wnioski końcowe}

Dzięki wdrożeniu innowacyjnej i pierwszej na świecie technologii wytwarzania rur ożebrowanych z wykorzystaniem najnowszej generacji laserów dużej mocy, powiązano dwie przeciwstawne cechy produktu i procesu, tj. uzyskano bardzo wysoką jakość produktu przy jednoczesnym zwiększeniu wydajności procesu w stosunku do tradycyjnego spawania MAG.

Rury ożebrowane wykonane techniką laserową charakteryzują się ciągłą spoiną z pełnym przetopem, równomiernym licem i prawidłowym kształtem. Uzyskanie ciągłej spoiny i pełnego przetopu $w$ rurach ożebrowanych spawanych laserem prowadzi do efektywniejszego odbioru ciepła, zwiększa się sprawność systemu oraz wydłuża czas użytkowania rur ożebrowanych.

Przy zastosowaniu odpowiednich parametrów spawania laserowego dla danego materiału, twardości złączy nie przekraczają $380 \mathrm{HV}$ w przypadku stali niskostopowych i $350 \mathrm{HV}$ dla stali chromowomolibdenowych. Opracowaną technologię poddano kwalifikacji zgodnie z wymaganiami normy PN EN ISO 15614-11. Rury ożebrowane wykonane w Energoinstalu na nowym stanowisku do spawania laserowego spełniają wymagania przepisów ciśnieniowych PN EN 12952 oraz niemieckich wytycznych VGB.

Wdrożenie technologii laserowej umożliwiło zwiększenie wydajności procesu spawania o ok. $600 \%$ i pozwoliło na znaczną redukcję kosztów procesu wytwarzania rur ożebrowanych. Oszczędności z wdrożenia spawania laserowego wynikają nie tylko ze zwiększenia prędkości spawania, ale również z niestosowania drutu elektrodowego, mniejszego zużycia energii elektrycznej (8-krotne) i zwiększenia kilkukrotnie mocy produkcyjnych bez zwiększania powierzchni wytwórczej zakładu.

\section{Literatura}

[1] Brockmann R.: TRUMPF Disk Laser, TRUMPF Laser, Schramberg, materiały informacyjne, 2008.

[2] PN-EN ISO 15614-11:2005 Specyfikacja i kwalifikowanie technologii spawania metali. Badanie technologii spawania: Spawanie wiązką elektronów i wiązką promieniowania laserowego.
[3] PN-EN ISO 13919-1:2002 Spawanie - Złącza spawane wiązką elektronów i wiązką promieniowania laserowego. Wytyczne do określania poziomów jakości według niezgodności spawalniczych. Część 1: Stal.

[4] PN-EN 12952-5:2011 Kotły wodnorurowe i urządzenia pomocnicze. Część 5: Wytwarzanie i budowa części ciśnieniowych kotłów. 